\title{
Coagulation and fibrinolytic activity of cerebrospinal fluid
}

\author{
MILNE ANDERSON, ${ }^{1} \mathrm{~K}$. B. MATTHEWS, AND J. STUART \\ From the Department of Haematology, Queen Elizabeth Hospital, Birmingham B15 2TH, UK
}

SUMMARY Fibrin/fibrinogen degradation products (fragments $\mathrm{D}$ and $\mathrm{E}$ ) were detected in cerebrospinal fluid in $23.4 \%$ of 252 patients admitted to a neurological/neurosurgical unit. Other coagulation proteins of low molecular weight (plasminogen and factor IX) were also present but larger $\cdot \overrightarrow{-}$ proteins (fibrinogen and factor V) were not. These findings are consistent with protein leakage across a blood-CSF barrier damaged by inflammatory, vascular, or neoplastic disease. Fibrin/ $/ \infty$ fibrinogen degradation products in cerebrospinal fluid after subarachnoid haemorrhage may not, 은 therefore, be a reliable index of increased fibrinolytic activity in the subarachnoid space and may be misleading when selecting patients for fibrinolytic blockade.

Proteins with coagulant or fibrinolytic activity are not normally detected by conventional bioassay methods in unconcentrated cerebrospinal fluid (CSF). Nevertheless, it is a well-known clinical observation that CSF specimens may clot in pathological conditions such as tuberculous meningitis. The products of fibrinolytic activity-fibrin/fibrinogen degradation products (FDP)-have been found in CSF after subarachnoid haemorrhage (Tovi, 1972; Tovi et al., 1972), in meningitis (Brueton et al., 1974, 1976), and in $18.5 \%$ of patients admitted to a district psychiatric unit (Hunter et al., 1974).

Relatively little is known of the underlying mechanisms whereby FDP and other coagulationfibrinolytic proteins appear in CSF. It has been assumed that the high CSF level of FDP after subarachnoid haemorrhage results from lysis of fibrin deposited around the bleeding point (Tovi, 1972; Tovi et al., 1972), but the expected increase in CSF plasminogen activator has either not been detected (Tovi et al., 1972) or only slight activity has been detected in an occasional patient (Tovi et al., 1973). Nevertheless, therapeutic inhibition of the presumed excess fibrinolytic activity of CSF has been recommended to prevent rebleeding after subarachnoid haemorrhage. Clinical studies have given encouraging results (Mullan and Dawley,

'Present address: Midland Centre for Neurosurgery and Neurology, Holly Lane, Smethwick, West Midlands B67 7JX.

Received for publication 14 November 1977
1968; Ransohoff et al., 1972; Nibbelink et al., 1975; Sengupta et al., 1976) and a controlled clinical trial is currently in progress (Maurice-Williams, 1977). In meningitis, in contrast, enhancement of CSF fibrinolytic activity using streptokinase and urokinase has been advocated for the removal of $\mathcal{Q}$ excess fibrin (Stewart, 1964; Newman and Stewart, 1965).

The present study was undertaken to determine the conditions in which these coagulation-fibrinolytic proteins appear in CSF, to assess their diagnostic value, and to investigate their origin.

\section{Patients and methods}

Cerebrospinal fluid was obtained by lumbar, ci- $\circ$ sternal, or ventricular puncture done for diagnostic or therapeutic purposes in 252 patients admitted to a neurological/neurosurgical unit. The CSF $(1.0 \mathrm{ml}) \stackrel{\equiv}{N}$ was collected directly into $0.1 \mathrm{ml}$ of $3.13 \%$ sodium $\sigma$ citrate in a plastic tube for measuring factor $\mathrm{V} \mathrm{N}$ (Wolf, 1953), factor IX (Hardisty and Ingram, 1965), స్心 plasminogen (De Vreker, 1965), and fibrinogen ${ }_{\sigma}^{\omega}$ (Diagen latex slide test; Diagnostic Reagents Limited). The specimens were transported at $\stackrel{0}{=}$

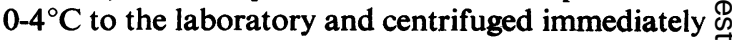
at $1600 \mathrm{~g}$ for five minutes at $4^{\circ} \mathrm{C}$. An additional $1.0 \mathrm{ml}$ of CSF was collected into aprotinin (250 units), and $0.1 \mathrm{ml}$ thrombin (final concentration $20 \stackrel{\mathrm{\Phi}}{\mathrm{D}}$ units $/ \mathrm{ml}$ ) was added before incubation at $37^{\circ} \mathrm{C}$ for $\frac{O}{\mathbb{D}}$ one hour followed by centrifugation and assay of the $\varrho$ supernatant for FDP (Thrombo-Wellcotest; Wellcome Reagents Limited). 
Plasminogen activator was estimated by adding citrated CSF to unheated fibrin plates (Astrup and Müllertz, 1952; Cash and Allan, 1967) within one hour of collection. Red cell counts in CSF were performed using an improved Neubauer counting chamber and CSF total protein was estimated by the method of Meulemans (1960) and Pennock et al. (1968). Statistical significance was determined by correlation coefficient and Student's $t$ test.

\section{Results}

Twenty-two patients who proved to be clinically normal with no neurological abnormality had normal concentrations of CSF coagulation proteins (Table 1). In the study of 252 patients (Table 2) FDP were detected in the CSF in $59(23.4 \%)$. Out of these 59 all but one also had a raised CSF protein, 42 had plasminogen in the CSF, and 26 had factor IX in the CSF. The larger molecular weight factor $\mathrm{V}$ and fibrinogen were not detected in any of the specimens.

Whenever thrombin-treated CSF gave a negative reaction with the Thrombo-Wellcotest antibody (that is, no detectable fragments $D$ and E) the corresponding citrated CSF specimen without thrombin always gave a negative reaction with the Diagen reagent (that is, no detectable fibrinogen). Whenever thrombin-treated CSF gave a positive reaction with the Thrombo-Wellcotest antiserum the corresponding citrated specimen gave either a weaker or a negative reaction with the Diagen test. This was also interpreted as an absence of detectable fibrinogen in view of the greater sensitivity of the latter test to fibrinogen as opposed to fragments D and E (Donati et al., 1973). These authors similarly used the combined technique to differentiate fibrinogen-related material in urine.

The patients were divided (Table 2) into clinical conditions in which increased permeability of the meningeal and choroidal capillaries with loss of integrity of the blood-CSF barrier might be expected (group 1) and conditions in which the barrier would normally be intact (group 2) (Schliep and Felgenhauer, 1974).

\section{GROUP 1}

Ten of the 13 patients with acute subarachnoid haemorrhage were studied within 96 hours of clinical onset and all showed two or more low molecular weight (LMW) coagulation proteins in the CSF. These included FDP, plasminogen, and/or factor IX. The three remaining patients underwent lumbar puncture 4-16 days after clinical onset and none showed more than one LMW coagulation protein in the CSF. In contrast, CSF from patients studied at a later stage after subarachnoid haemorrhage (group 2) showed no abnormality.

Eight out of 11 postoperative patients had two or more LMW coagulation proteins in their CSF and had recently undergone major craniotomies for syringomyelia (6) or for intracranial haemorrhage (2). In contrast, the three patients who had undergone less traumatic procedures-ventriculography (2) or insertion of a Spitz-Holter valve (1)-had no CSF abnormality.

The seven infected patients with two or more LMW coagulation proteins in their CSF suffered from acute bacterial meningitis, while three patients without this CSF abnormality had suffered only mild viral encephalitis.

Two out of the five patients with a spinal tumour had two or more LMW coagulation proteins in their CSF and they had complete myelographic block from metastases. The three who did not have the CSF abnormality (one meningioma, one metastasis, and one angiolipoma) had only partial block. Four patients with an intracranial tumour (two chromophobe adenomas and two acoustic neuromas) had two or more LMW coagulation proteins in their CSF while eight did not, and the CSF from four of the eight (two gliomas, one craniopharyngioma, and one dermoid) was completely normal.

Patients with cerebrovascular disease had a much lower incidence of LMW coagulation protein in the CSF. The three who did suffered from intracranial haemorrhage, spinal cord infarction, and cerebral atherosclerosis respectively.

GROUP 2

None of the five patients from whom ventricular CSF was obtained at craniotomy for clipping of an aneurysm up to two months after haemorrhage (non-acute subarachnoid) had any CSF abnormality. Only nine out of the whole group of 188 patients had two or more LMW coagulation proteins in their CSF. Three, classified as 'degenerative', had peripheral neuropathies with a gross rise in CSF protein, one had an acute disc prolapse (lumbar spondylosis group), one had ischaemic myelopathy (cervical spondylosis group), and one had a longstanding Spitz-Holter valve for hydrocephalus (miscellaneous group). The two patients in whom no neurological abnormality was detected (NAD) and the one epileptic had not developed any new neurological abnormality after full investigation and 18 months' follow-up.

The presence of two or more LMW coagulation proteins in the CSF was not associated with a raised CSF red cell count except in the acute subarachnoid haemorrhage and postoperative patients. If these patients are excluded only four out of 25 
Table 1 Range of normal concentrations for CSF proteins obtained from 22 patients who proved to be clinically normal. Total protein values represent the laboratory normal range

\begin{tabular}{|c|c|c|}
\hline CSF protein & Concentration & Molecular weight* \\
\hline $\begin{array}{l}\text { Coagulation proteins } \\
\text { FDP (fragments D and E) } \\
\text { Plasminogen } \\
\text { Factor IX } \\
\text { Factor V } \\
\text { Fibrinogen }\end{array}$ & $\begin{array}{l}<2 \mu \mathrm{g} / \mathrm{ml} \dagger \\
<20 \text { units } \dagger \\
<1 \% \dagger \\
<1 \% \dagger \\
\text { nil }\end{array}$ & $\begin{array}{r}50-83000 \\
89000 \\
50000 \\
290000 \\
340000\end{array}$ \\
\hline $\begin{array}{c}\text { Total protein } \\
\text { Lumbar } \\
\text { Cisternal } \\
\text { Ventricular }\end{array}$ & $\begin{array}{l}<0.45 \mathrm{~g} / 1 \\
<0.25 \mathrm{~g} / 1 \\
<0.15 \mathrm{~g} / 1\end{array}$ & $\begin{array}{l}\text { Predominantly } \\
45-90000\end{array}$ \\
\hline
\end{tabular}

patients with a raised CSF red cell count had LMW coagulation proteins. A raised CSF total protein (predominantly of MW 45-90 000) correlated significantly with raised FDP $(r=0.46, P<0.001)$ and with raised plasminogen $(\mathrm{r}=0.842, \mathrm{P}<0.001)$ but not raised factor IX. A correlation between CSF plasminogen and total protein in various neurological disorders has previously been reported (Wu et al., 1973).

The level of plasminogen activator in CSF was measured in 18 of the patients with LMW coagula- ation proteins in their CSF. A clear zone of lysis of $\stackrel{0}{\vec{*}}$ the fibrin plate was observed in seven patients but 을 there was no correlation with clinical diagnosis or $\overrightarrow{\vec{F}}$ the type of LMW coagulation protein present. Only one of the four patients with acute subarachnoid haemorrhage who were tested showed an increased zone of fibrin lysis; his CSF was tested within 24 hours of clinical onset compared with three, six, and $O$ 11 days for the others.

\section{Discussion}

Fibrin/fibrinogen degradation products may appear in CSF under pathological conditions even with a? normal serum FDP level (Hunter et al., 1974; Brueton et al., 1976), but the assumption that theirir presence in CSF is solely a consequence of increasedoo CSF fibrinolysis (Tovi, 1972; Hunter et al., 1974) now seems unlikely. We found FDP in the CSF of $23.4 \%$ of patients undergoing diagnostic lumbar or ventricular puncture compared with $18.5 \%$ in and earlier report (Hunter et al., 1974). Filtration of protein into the CSF compartment is known to be inversely related to molecular size (Schliep andoo Felgenhauer, 1974), and these low molecular weight FDP (fragments D and E) were present in associations with other coagulation proteins of similar molecular size which are also not normally detectable in CSF ڤ

These proteins were found in patients with in $-\frac{\Phi}{2}$

Table 2 Results for patients in group 1 (loss of integrity of blood-CSF barrier) and group 2 (normally intact blood-CSF barrier)

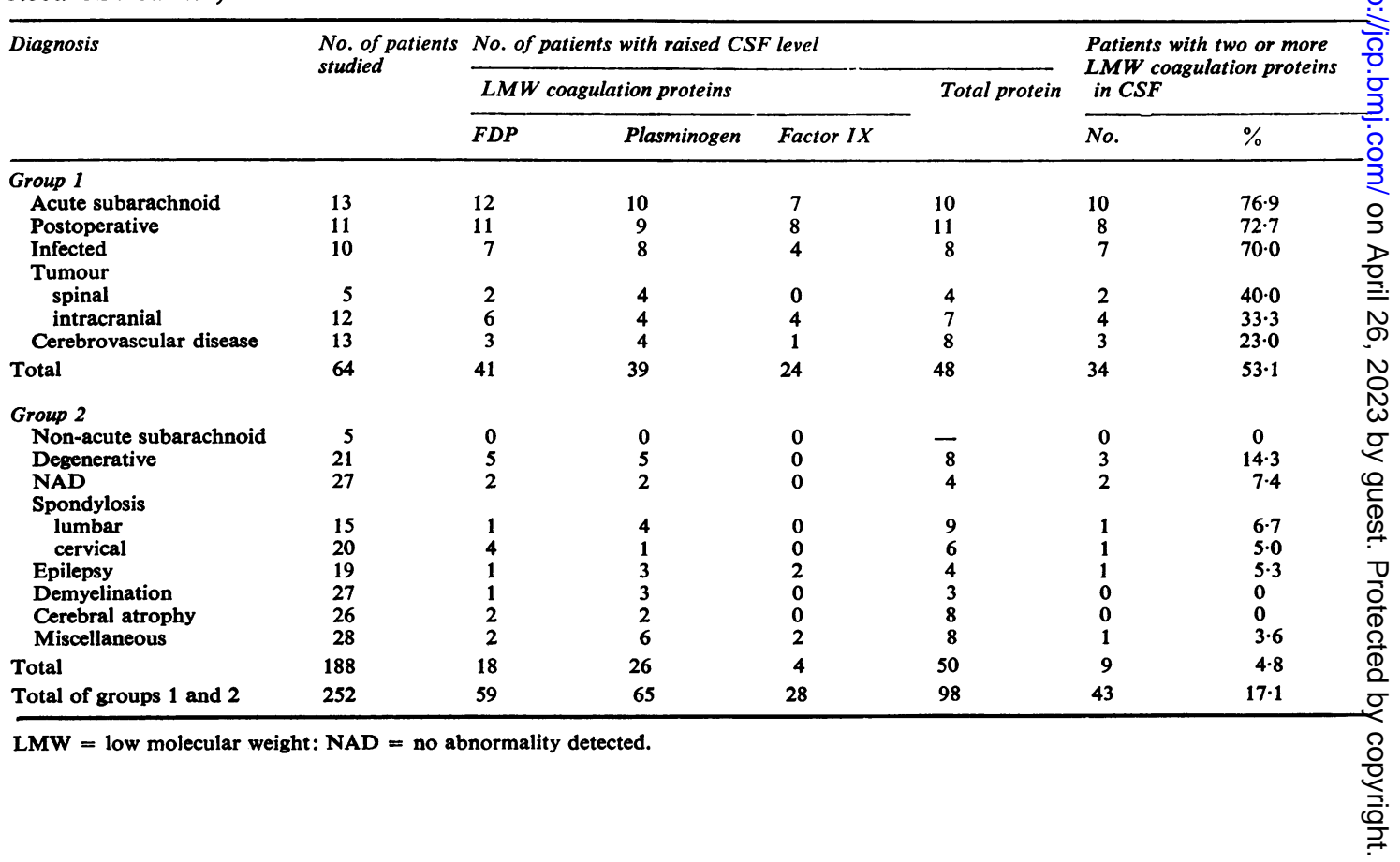


flammatory, vascular, and neoplastic conditions, which are known to increase the permeability of meningeal and choroidal capillaries, and the findings are consistent with protein leakage across a damaged blood-CSF barrier. Non-specific damage to this barrier is common to various neurological conditions (Schliep and Felgenhauer, 1974) and the presence of these coagulation proteins is unlikely to provide any further discriminant diagnostic function. A similar finding for CSF immunoglobulin and complement in meningitis was reported by Whittle and Greenwood (1977).

The relative contribution of increased permeability of the blood-CSF barrier to FDP, as opposed to their local generation by fibrinolysis, is likely to vary in different pathological conditions. This is analogous to the source of origin of FDP in urine in glomerulonephritis and the nephrotic syndrome (Clarkson et al., 1971; Naish et al., 1974; Hall et al., 1975) and of FDP in peritoneal and pleural fluids (Benz, 1968; Svanberg and Åstedt, 1975; Åstedt et al., 1976). The presence of raised CSF but not serum FDP is not an argument against leakage across the blood-CSF barrier. Intravascular thrombosis and clot lysis within cerebral vessels may generate a high local concentration of FDP that can leak into CSF but cannot reach, or may be diluted in, the blood of the systemic circulation.

Clinical trials of fibrinolytic inhibition in subarachnoid haemorrhage should therefore include a serial study of both FDP and plasminogen activator in CSF, particularly in the control group, since this may be of prognostic value. Our limited data suggest that these proteins usually disappear from the CSF within three to four days and their persistence (Tovi et al., 1973; Smith and Upchurch, 1973; Brueton et al., 1976) may indicate a continuing local lesion. The selection of patients for antifibrinolytic therapy, however, should not be based on the assumption that FDP in the CSF necessarily reflects increased fibrinolytic activity in the subarachnoid space.

Details from this study were presented to the British Society for Haematology, 1976. We are indebted to the Central Birmingham Health District Trust Funds for financial support and to the neurologists and neurosurgeons of the West Midlands region for allowing us to study their patients.

\section{References}

Åstedt, B., Adielsson, G., and Mattsson, W. (1976). Fibrin/fibrinogen degradation products in pleural exudate (Letter). Lancet, $2,414$.
Astrup, T., and Müllertz, S. (1952). The fibrin plate method for estimating fibrinolytic activity. Archives of Biochemistry and Biophysics, 40, 346-351.

Benz, J. J. (1968). Clotting factors and fibrinogen split products in the extravascular space. Thrombosis et Diathesis Haemorrhagica, 19, 226-235.

Brueton, M. J., Breeze, G. R., and Stuart, J. (1976). Fibrin-fibrinogen degradation products in cerebrospinal fluid. Journal of Clinical Pathology, 29, 341-344.

Brueton, M. J., Tugwell, P., Whittle, H. C., and Greenwood, B. M. (1974). Fibrin degradation products in the serum and cerebrospinal fluid of patients with group A meningococcal meningitis. Journal of Clinical Pathology, 27, 402-404.

Cash, J. D., and Allan, A. G. E. (1967). Effect of mental stress on the fibrinolytic reactivity to exercise. British Medical Journal, 2, 545-548.

Clarkson, A. R., MacDonald, M. K., Petrie, J. J. B., Cash, J. D., and Robson, J. S. (1971). Serum and urinary fibrin/fibrinogen degradation products in glomerulonephritis. British Medical Journal, 3, 447-451.

De Vreker, R. A. (1965). A technique for routine evaluation of plasminogen in humans during streptokinase therapy. Acta Haematologica, 34, 305-320.

Donati, M. B., Semeraro, N., and Vermylen, J. (1973). Detection of fibrinogen antigens with two latex techniques applied to urine concentrates. Journal of Clinical Pathology, 26, 760-763.

Hall, C. L., Pejhan, N., Terry, J. M., and Blainey, J. D. (1975). Urinary fibrin/fibrinogen degradation products in nephrotic syndrome. British Medical Journal, 1, 419-422.

Hardisty, R. M. (1974). The haemostatic mechanism. In Blood and its Disorders, edited by R. M. Hardisty and D. J. Weatherall, pp. 223-267. Blackwell, Oxford.

Hardisty, R. M., and Ingram, G. I. C. (1965). Bleeding Disorders: Investigation and Management, p. 307. Blackwell, Oxford.

Hunter, R., Thomson, T., Reynolds, C. M., and Pitcher, P. M. (1974). Fibrin/fibrinogen degradation products in cerebrospinal fluid of patients admitted to a psychiatric unit. Journal of Neurology, Neurosurgery, and Psychiatry, 37, 249-251.

Maurice-Williams, R. (1977). Personal communication.

Meulemans, O. (1960). Determination of total protein in spinal fluid with sulphosalicylic and trichloracetic acid. Clinica Chimica Acta, 5, 757-761.

Mullan, S., and Dawley, J. (1968). Antifibrinolytic therapy for intracranial aneurysms. Journal of Neurosurgery, 28, 21-23.

Naish, P., Evans, D. J., and Peters, D. K. (1974). Urinary fibrinogen derivative excretion and intraglomerular fibrin deposition in glomerulonephritis. British Medical Journal, 1, 544-546.

Newman, R. L., and Stewart, G. T. (1965). The use of fibrinolytic activators in meningitis and similar conditions. Archives of Disease in Childhood, 40, 235-242.

Nibbelink, D. W., Torner, J. C., and Henderson, W. G. (1975). Intracranial aneurysms and subarachnoid hemorrhage. A co-operative study. Antifibrinolytic therapy in recent onset subarachnoid hemorrhage. Stroke, 6, 622-629. 
Pennock, C. A., Passant, L. P., and Bolton, F. G. (1968). Estimation of cerebrospinal fluid protein. Journal of Clinical Pathology, 21, 518-520.

Ransohoff, J., Goodgold, A., and Benjamin, M. V. (1972). Preoperative management of patients with ruptured intracranial aneurysms. Journal of Neurosurgery, 36, 525-530.

Schliep, G., and Felgenhauer, K. (1974). The $a_{2}$-macroglobulin level in cerebrospinal fluid; a parameter for the condition of the blood-CSF barrier. Journal of Neurology (Berlin), 207, 171-181.

Sengupta, R. P., So, S. C., and Villarejo-Ortega, F. J. (1976). Use of epsilon aminocaproic acid (EACA) in the preoperative management of ruptured intracranial aneurysms. Journal of Neurosurgery, 44, 479-484.

Smith, R. R., and Upchurch, J. J. (1973). Monitoring antifibrinolytic therapy in subarachnoid haemorrhage. Journal of Neurosurgery, 38, 339-344.

Stewart, G. T. (1964). Fibrinolytic therapy in meningitis and ventriculitis. Journal of Clinical Pathology, 17, 355-359.

Svanberg, L., and Åstedt, B. (1975). Coagulative and fibrinolytic properties of ascitic fluid associated with ovarian tumors. Cancer, 35, 1382-1387.

Tovi, D. (1972). Studies on fibrinolysis in the central nervous system with special reference to intracranial haemorrhages and to the effect of antifibrinolytic drugs. Umed University Medical Dissertations, 8? $1-50$.

$\overrightarrow{\vec{F}}$

Tovi, D., Nilsson, I. M., and Thulin, C. A. (1972)丞 Fibrinolysis and subarachnoid haemorrhage. In hibitory effect of tranexamic acid. A clinical studyo Acta Neurologica Scandinavica, 48, 393-402.

Tovi, D., Nilsson, I. M., and Thulin, C. A. (1973)ब Fibrinolytic activity of the cerebrospinal fluid afte? subarachnoid haemorrhage. Acta Neurologica Scandes inavica, 49, 1-9.

Whittle, H. C., and Greenwood, B. M. (1977). Cerebro: spinal fluid immunoglobulins and complement in meningococcal meningitis. Journal of Clinical Pathology 30, 720-722.

Wolf, P. (1953). A modification for routine laboratory use of Stefanini's method of estimating factor $\mathrm{V}$ activity in human oxalated plasma. Journal of Clinical Path ology, 6, 34-38.

Wu, K. K., Jacobsen, C. D., and Hoak, J. C. (1973) Plasminogen in normal and abnormal human cere brospinal fluid. Archives of Neurology, 28, 64-66.

Requests for reprints to: Dr John Stuart, Department ot Haematology, Queen Elizabeth Hospital, Birminghanojo B15 2TH. 